\title{
Controlled Synthesis of $\mathrm{ZnWO}_{4}$ Nanostructure and Effects on the Photocatalytic Performances
}

\author{
Jie Lin ${ }^{1}$, Jun Lin ${ }^{2 *}$, Yongfa Zhu ${ }^{1 *}$ \\ ${ }^{1}$ Department of Chemistry, Tsinghua University, Beijing, 100084, P. R. China; \\ ${ }^{2}$ Department of Chemistry, Renmin University of China, Beijing 100872, P. R. China
}

Corresponding author 1: E-mail: zhuyf@tsinghua.edu.cn

Corresponding author 2: E-mail: jlin@,chem.ruc.edu.cn

Supporting Information Available 


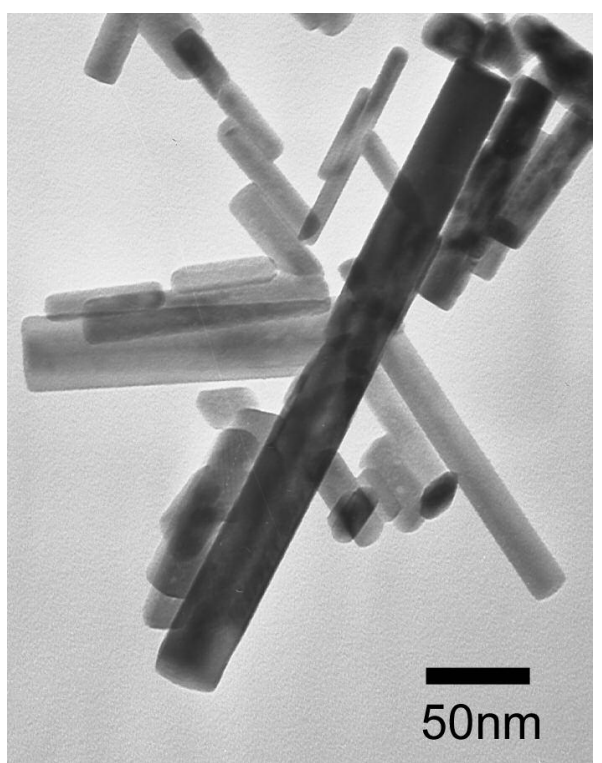

S1. TEM image of $\mathrm{ZnWO}_{4}$ sample prepared at $130{ }^{\circ} \mathrm{C}$ for $48 \mathrm{~h}$ and then retreated at $180{ }^{\circ} \mathrm{C}$ for $48 \mathrm{~h}$ again.

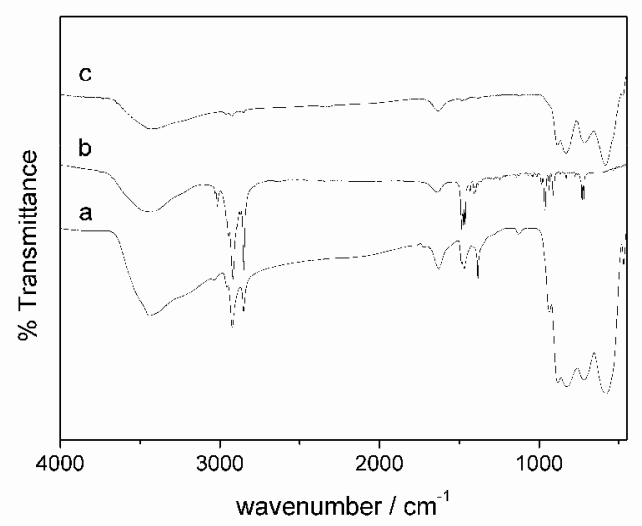

S2. Fourier transform infrared spectra (FT-IR) spectra of samples: a) $\mathrm{ZnWO}_{4}$ prepared at $120{ }^{\circ} \mathrm{C}$ for $120 \mathrm{~h}$ in hydrothermal condition. b) $\mathrm{C}_{16}$ TAB. c) sample a) annealed at $450{ }^{\circ} \mathrm{C}$ for $2 \mathrm{~h}$. 


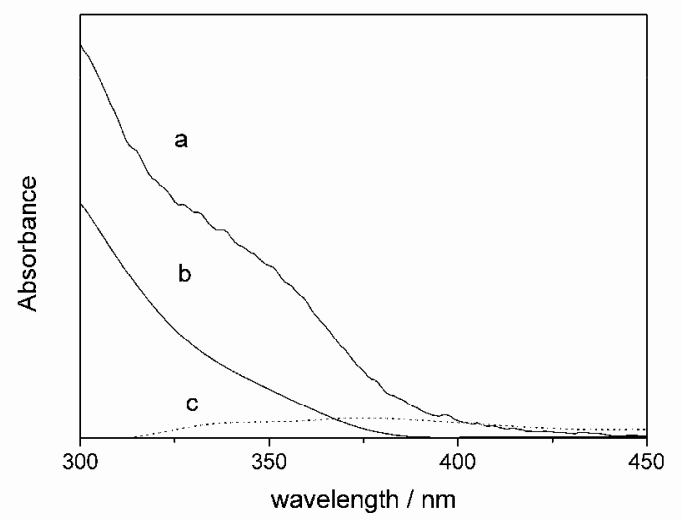

S3. Diffuse reflectance absorption spectra of $\mathrm{ZnWO}_{4}$ samples: a) $\mathrm{ZnWO}_{4}$ prepared at $120{ }^{\circ} \mathrm{C}$ for $120 \mathrm{~h}$ in hydrothermal condition. b) sample a) annealed at $450{ }^{\circ} \mathrm{C}$ for 2 h. c) $\mathrm{C}_{16} \mathrm{TAB}$.

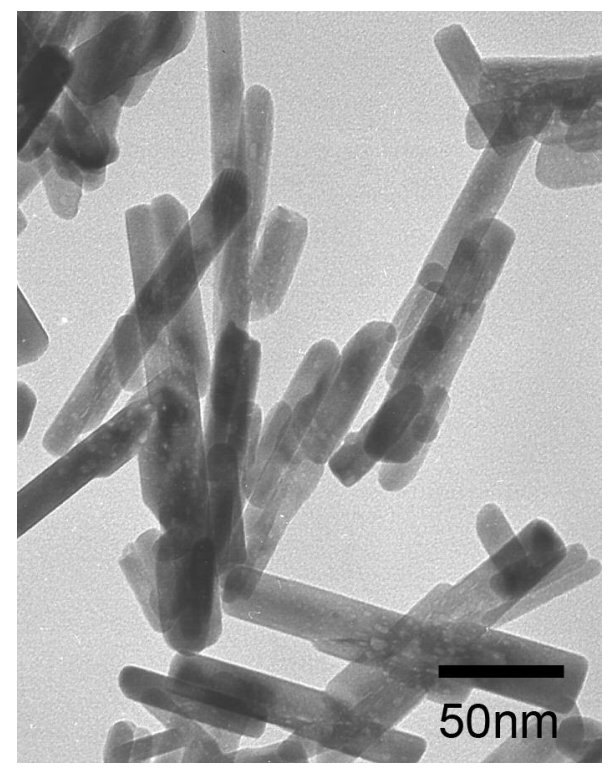

S4. TEM image of $\mathrm{ZnWO}_{4}$ sample prepared at $120{ }^{\circ} \mathrm{C}$ for $120 \mathrm{~h}$ annealed at $450{ }^{\circ} \mathrm{C}$ for $2 \mathrm{~h}$ again. 